\title{
Reading skills for weak learners
}

\section{Madeline Lutjeharms}

\section{OpenEdition}

\section{Journals}

Electronic version

URL: http://journals.openedition.org/asp/3149

DOI: $10.4000 /$ asp.3149

ISSN: 2108-6354

\section{Publisher}

Groupe d'étude et de recherche en anglais de spécialité

\section{Printed version}

Date of publication: 1 December 1997

Number of pages: 239-253

ISSN: 1246-8185

\section{Electronic reference}

Madeline Lutjeharms, «Reading skills for weak learners », ASp [Online], 15-18| 1997, Online since 06 November 2012, connection on 19 April 2019. URL : http://journals.openedition.org/asp/3149 ; DOI : 10.4000/asp.3149

This text was automatically generated on 19 April 2019

Tous droits réservés 


\title{
Reading skills for weak learners
}

\author{
Madeline Lutjeharms
}

\section{Introduction: Reading and foreign language acquisition in VOLL}

1 Learners in vocationally-oriented schools may have very varied future foreign language (FL) needs according to the type of training, from oral proficiency in hotel business to reading comprehension of technical language as used in instructions manuals. However, even in the same professional surroundings different needs may appear. A receptionist may have to read a note or a technician may haveto talk to a colleague. Besides, professional flexibility has become indispensable for improving the chances of the learner on the labour market. This has consequences for vocationally-oriented language learning (VOLL). Although it is sensible and even necessary in VOLL to consider the most typical use of language for a certain career and adapt skill training and vocabulary acquisition to comply with it, it is useful to prepare the learners for what could become necessary autonomous acquisition of other skills and a different vocabulary. It will be argued that learning how to work with FL texts, especially written texts, which are easily available, as a resource for further autonomous FL acquisition is a way of achieving this goal, even for weak learners.

2 To focus on comprehension has a number of advantages for learning. Written or spoken texts provide input, without which it is not possible to learn a language since perception has to come before production. Texts, especially written texts, provide input that can easily be repeated for practising and memorizing. Besides, they offer many possibilities for incidental learning. Texts offer words and structures in meaningful contexts, which facilitates the construction of connections and elaborations in long term memory, which is necessary for retention. Another advantage of written texts in a learning situation is that the processing rate is controllable.

In what follows attention will first go to the problems facing weak learners when reading L1. In order to understand those problems some explanation on memory and information processing is required. Then the problems of readers in a foreign language, especially of 
weak readers, will be dealt with. It will be shown, how important reading is for improving linguistic skills. If learners are to be involved in a lot of reading, they need to be motivated. Some research data on reading and foreign language acquisition can help us organize teaching more efficiently. A short review of relevant data will be presented. Finally, practical work in class is considered with some proposals on how to organise teaching and suggestions for assignments.

\section{Reading and the weak reader}

Reading is a very complex process of which all aspects cannot yet be described. Besides, there is not only one type of reading process. According to reading purpose, conditions and competence reading styles will vary. The most important contribution to reading research comes from cognitive psychology with many experimental data on aspects of the reading process, mainly on L1 reading and on the lower processing levels, i.e. word recognition and syntactic analysis. Some aspects of the theory based on these data are relevant for FL reading and/or for the reading skills of weak learners. In applied linguistics empirical research on the FL reading process deals mainly with higher processing levels (text comprehension). These two sources of information are therefore complementary.

\subsection{Reading and the functioning of memory}

In working memory two processing types are observed:

1. Automatic processing, which is fast, parallel, i.e. different things can be done at the same time, without capacity limitations and free of effort. In the case of linguistic fluency the lower levels of the reading process are dealt with automatically.

2. Conscious or controlled processing, which is attentional, limited in capacity and demands an effort. Only about 7 units can be processed simultaneously. Such a unit can be a letter or a number, but also a complex theory. In order to improve and accelerate processing, more complex units have to be developed, e.g. words or morphemes instead of single letters. Conscious processing is required for content matter (semantic level) and for new, unexpected or illogical information.

Rehearsal, which means maintaining verbally coded information in working memory, is essential for conscious processing. Rehearsing happens acoustically in the phonological loop, one of the two "slave systems" to the central executive that Baddeley and Hitch propose for working memory (see Gathercole \& Baddeley 1993: 4). Whether rehearsal implies (sub)articulatory activity or has a completely abstract phonological basis is not clear from research data, but subvocal control processes have been found during the processing of complex sentences (Gathercole \& Baddeley 1993: 16, 204ff., 219). Whether phonological recoding is necessary for lexical access, i.e. for recognizing the word as part of the mental lexicon, is not sure, although many indications have been found (for a summary of research data, see Lutjeharms 1994c: 44ff.; also Daneman \& Reingold 1995: 31, who consider phonological recoding as a by-product rather than as a route to lexical access).

During perception expectations based on experience interact with the incoming information from perceived cues. Correct expectations facilitate processing, whereas 
wrong or imprecise expectations have to be adapted to the incoming information during processing and are very demanding on working memory capacity.

In order to be a good reader, as much knowledge as possible has to be activated automatically. When the processing of linguistic form takes place automatically, as is the case for a fluent L1 reader, all the attention can be concentrated on understanding content. Unknown words will slow down the process or, if they are ignored, may result in imprecise or even erroneous interpretations. The more we know about the content the higher our expectations and the faster the processing.

\subsection{Poor and strong readers: similarities and differences}

Weak learners often have difficulty reading their native language reading skills and learning tend to be very much interdependent in formal education. Differences in intelligence have been found for poor and good readers (Sahu \& Kar 1994: 17). Reading problems of poor L1 readers may be due to limited working memory capacity, i.e., to a smaller memory span (Levy Hinchley 1990: 125f.). Because of these limitations they cannot process a large number of cues on the conscious level. When weak learners are confronted with complex or contradictory information it is only partly dealt with or even not at all (for L1, see Brown 1990).

Another factor is slow processing of linguistic form, e.g. because of deficits in phonological recoding or because of slow word recognition. Due to lack of efficient word recognition skills poor readers have been found repeatedly to rely more on context in trying to derive meaning than is the case for skilled readers (Juel $1995: 147$; Stanovich \& Stanovich 1995: 90ff.; Wong \& Underwood, 1996). Hypothesis-testing is often the only way for poor readers to arrive at some (often erroneous) meaning (Juel 1995: $146 \mathrm{ff}$.). Skilled readers on the contrary pay close attention to (all) the words in a text, which they recognize very fast (Perfetti 1995: 106ff.). They use context for interpretation on the semantic level, not for lower level processing, because they do not need to.

11 Problems on the level of processing linguistic form elicit conscious processing. Memory capacity is then lacking to understand content. A great deal of reading activity in order to acquire automatic routines for lower level processing is therefore the best way of improving reading skills. For children learning to read L1 «building up knowledge of subword spelling sound correspondences appears to be a necessary prerequisite of fluent reading » (Stanovich \& Stanovich 1995: 95).

\section{Reading in a foreign language}

\subsection{Some research data with relevance for learning to read a foreign language}

12 An extensive description of the reading process, and one on which there is complete agreement, does not exist and in actual fact a number of different processes would have to be described. Only some experimental data on the FL reading process are available, but some data from the L1 reading process have relevance for FL learning and teaching.

13 In an FL the sound does not normally help to find the meaning as in beginning L1 reading. Nevertheless, even if reading comprehension is the only target, knowledge about 
spelling-sound correspondences is required, not only because of possible acquisition of other skills later on or for motivational reasons or in order to be able to ask for the meaning of a word in an intelligible way or for any other practical reason. The main reason for this is the role of the phonological code in working memory, which in an FL may be necessary even for lexical access and syntactic analysis, for as long as these are not automatized (Segalowitz \& Hébert 1990). Another important reason is the role of the phonological code for vocabulary acquisition (Papagno, Valentine \& Baddeley 1991), for which rehearsal is a very common strategy. Rehearsal, often even articulation, is necessary for looking up a word in a dictionary.

Even very fluent L2 readers read more slowly than in their native language, because lower level processing, like word recognition, is slower (Segalowitz 1986; Segalowitz, Poulsen Komoda 1991).

Because of linguistic deficits FL readers, like poor L1 readers, rely more strongly on contextual information to understand word meaning, but as a result of lack of command of syntactic and textual structures, the quality of this contextual information may be insufficient (Segalowitz 1986). Vocabulary acquisition is therefore one of the main strategies to improve reading skills. Morphemes have been found to play an important role in both L1 and L2 word recognition (Lutjeharms 1991 and 1994b). Exercises on morphologically defined parts of words shorten reaction times for lexical access to all words with these morphemes (Kirsner, Speelman \& Schofield 1993: 135). Therefore recognition exercises on word stems, affixes and inflectional morphemes are useful.

Syntactic features tend to be repeated frequently during text processing as there are relatively few of them. The importance of syntax for learning to read an FL depends very much on the relation between the target language and the native or other fluent languages. Native speakers of English or French learning German or Dutch for instance have to acquire a new strategy in order to decode flexible word order, whereas native speakers of German or Dutch have no problems with SVO order, which they know from their L1. FL learners first transfer L1 strategies, but adopt more target language strategies as their linguistic skills increase. However L1 sentence comprehension strategies that do not conflict with a correct interpretation of the FL structure are maintained (McDonald \& Heilenman 1991; Koda 1993). The best way of finding suitable exercises for improving syntactic decoding are contrastive analysis, error analysis (of wrong answers to content questions, faulty translations and erroneous segmentation) or introspection data, as direct observation is not possible during reception.

Bernhardt (1993) showed how dangerous knowledge-based inferencing can be, when a text is not well understood. Misunderstanding text content as a result of prior knowledge can promote wrong interpretations of word meaning or structure (Bernhardt 1993: 161,146; Lutjeharms 1988: 274). It is important that assignments should not be too difficult so as to avoid wild guessing. Sometimes, however, guessing or inferring with the help of prior knowledge is the only way to arrive at some kind of meaning. Attention should therefore be paid to good inference strategies. Adequate prior knowledge can be a great help for understanding and should be used whenever possible using any source. 


\section{Importance of motivating learners to read}

18 As has already been mentioned, weak learners usually find it difficult to process information because of limitations on the level of working memory capacity. Reading an FL may to them seem like an insuperable difficulty. If linguistic form requires attention in order to be understood, semantic processing may not even be attempted.

\subsection{Reading activities seen as skill training}

19 FL learners are weak readers for as long as linguistic knowledge is too deficient for automatic processing of form. They have to rely partly on strategies typical of the weak L1 reader like guessing, but even if there is enough information to guess the meaning of a word, a sentence or a whole paragraph, weak learners are often not capable of using it. A good native language reader, on the other hand, will be good at guessing, especially if text content is not unfamiliar.

Kolers maintained that a task such as reading a word or sentence, for example, requires a particular set of sensory-perceptual and conceptual analyzing operations, and that engaging these operations has the same effect as practising a skill - it increases fluency and efficiency with which they can be carried out subsequently (Graf \& Masson 1993: 5; Kolers 1975).

Skill acquisition and repetition priming seem to share many features. Repetition priming is the observation "that performance on a variety of simple tasks is facilitated when subjects are exposed to the same stimulus at some earlier point in an experimental sequence " and this implicitly, without being conscious of the repetition (Kirsner Speelman \& Schofield 1993: 119). By repeated reading activities nonsemantic conscious processing becomes an automatic process, as automatic subroutines develop, that are activated to allow for higher level, i.e., semantic, processing. In other words weak readers should be motivated to read as much as possible in order to improve their reading skills, for each reading activity. In particular, reading the same words and structures over and over again, in the same or in a different context, reinforces skill acquisition.

21 Texts can be used for activities that give insight into the language. Insight or language awareness, which results from attention to certain features, e.g., grammatical points or morphemes, leads to explicit or consciously controlled knowledge (knowledge about something, declarative knowledge).

Explicit knowledge facilitates implicit knowledge by making learners conscious of

linguistic features in the input which might otherwise be ignored (Ellis 1990: 195).

Implicit knowledge (being able to use the knowledge, procedural knowledge) develops through incidental learning, i.e., through confrontation with the input and through practice. It results in the development of a mental lexicon for the FL, which is necessary to enable the learner to process linguistic form at least partly on an automatic level. Both types of learning play an important role in FL learning, but explicit forms of learning seem to be the most advantageous (Berry \& Dienes 1993: 139, 35). 


\subsection{Autonomous learning : a successful experiment}

How can weak learners be motivated to read as much as possible? The working group on strategies of the Council of Europe's VOLL workshops $6 \mathrm{~A}$ and $6 \mathrm{~B}$ decided to adopt autonomous learning in class as a way of motivating weak learners (average age 17; for reports on actual work in class by EFI, teachers from Finland and Sweden, members of the working group, see Niemela 1995 and Ohman 1995; their oral reporting was an important source for what follows; see also Lutjeharms 1992). This learner-centred approach proved to be very challenging both for learners and teachers.

Institutional learning situations may not seem an ideal context for autonomous learning, but a solution was found in combining periods with more traditional teaching and autonomous work. Some texts and tasks were compulsory for all learners to cover the vocational field, but the learners worked on these independently and at their own pace, alone or in pairs as they preferred, using their textbooks and a bilingual dictionary. Besides the compulsory work, learners had to draw a list of what they planned to do during a certain period. During this period they were told to regularly check how far they were from achieving the next subgoal. It was striking to see that, with no interference from the teacher, if learners can set their own goals they do not lag behind. There is an atmosphere in the class that makes everybody work. In the beginning it is difficult for the teacher to learn not to interfere. Some Dutch-speaking Belgian teachers of German, who are now adopting a comparable approach of autonomous learning talked about the difficulties they experienced with their own role in the class ("Wir milssen vollig umdenken "), whereas learners seemed to have no problems adopting this new approach (but see Niemela 1995, some of her learners were confused at first). The role of the teacher is one of an adviser, facilitator and supporter. The teachers reported that they get to know their learners better as they can work with them on an individual basis or in small groups, which they find very rewarding.

The learners were provided with many short texts for reading, from among which they could select. Because of this they could concentrate on areas of particular interest to themselves. To choose a text is a reading task in itself, as many titles will be read and there will be some skimming. Together with the texts there are tasks and general lists with questions and instructions on reading strategies, like the use of different reading styles: scanning, skimming and receptive reading; of contextual guessing and reflecting on how the guess was made. The tasks encourage the learners to observe and discuss their own learning processes and strategies. For weak learners it came as a revelation, to discover that they can work with text in different ways, e.g. finding the main points in a text or looking for specific information only, using it for observing or learning vocabulary or grammatical features etc. Better readers show more flexibility in using different strategies for different types of tasks (Sasaki 1993). Learners can always ask to be given more texts or be tested by the teacher. Productive skills were not neglected. "Speaking was practised in pairs or with the teacher " (Niemela 1995:76). The learners had to get used to marking and correcting their own work (keys were provided). As a result, they get very much involved in correcting their own mistakes, a process from which much is learned. They start thinking about their mistakes and sometimes argue about correct solutions with friends or teacher. They also correct each other's work. In other words, they learn the process, the product and the evaluation. 


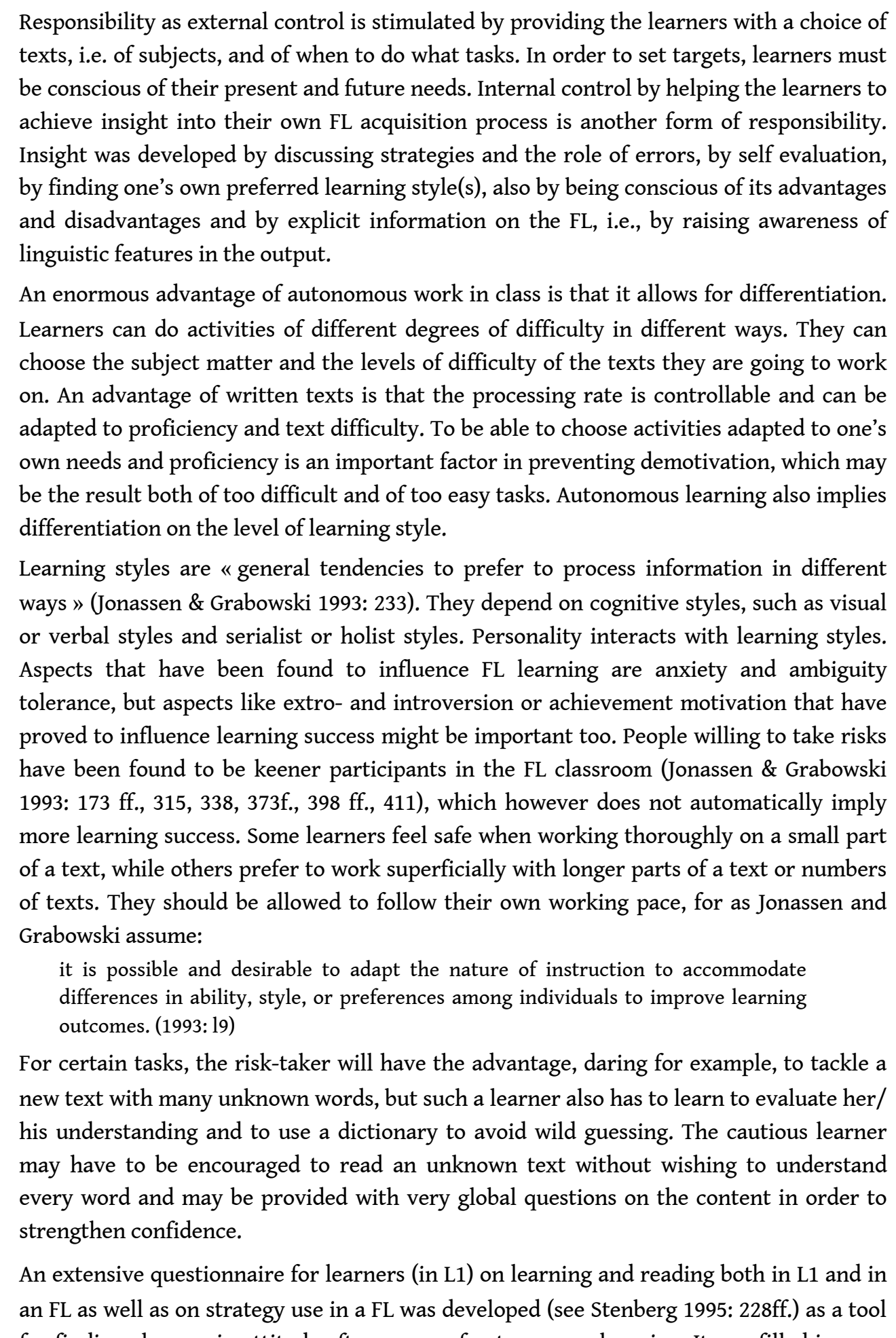
for finding changes in attitude after a year of autonomous learning. It was filled in once before and once after the teaching period. Attitudes do not seem to change very much, but when they do, it tends to be towards more autonomy. That the changes were so small shows some consistency in the answers of the learners. An unexpected result was that the questionnaire proved to be a good starter to make learners conscious of their own learning goals and styles. Although most participants (besides Finland and Sweden also learners in the UK and Belgium participated) are considered to be weak learners whom 
we had not expected to like writing, we were astonished to see how they really tried to analyse their own attitudes (for results see Lutjeharms 1994a).

Both teachers and learners were happy with this new approach.

There is a nice atmosphere in the classroom. All the classes that I have introduced to autonomous learning have liked it so much they demanded to go on (they) thought they learnt more working autonomously. (Niemela 1995: 78)

While working in the «traditional» teacher-centred way, there were always problems with discipline and motivation. This time everybody had worked very energetically and there were no discipline problems at all, even though the students had worked on different subjects. (Ohman 1995: 238)

\section{Some remarks on work in class}

\subsection{How to facilitate the task of the learner}

The best way to improve semantic processing is to develop automaticity in lower level processing. Assignments that elicit some form of semantic processing are important as a first confrontation with a text, since learners need to bear meaning in mind when completing rather form-oriented exercises later on. Traditional questions like: "Why did you choose this text?" "What is it about?" "Is the content what you expected it to be?" "Does the text give information on X?" "What does it say?", may be helpful. Beginners may answer and discuss such questions in L1. Practising reading styles is useful, asking the learner first to look for a specific item of information, such as a word, name or number (scanning), then to read fast in order to get some idea of the content of the text (skimming) and finally to read more thoroughly to get the gist of it (receptive reading).

Tasks that induce repeated reading of the same text, which is required for both skill and language acquisition, should be as varied as possible and include many easy tasks like recognition exercises (underline all the articles, certain verb forms, conjunctions etc. or specific information, such as indications of time or place, numbers, negations) or work on vocabulary. For beginners with minimal FL competence the assignment may be to look for familiar words or parts of words, for more advanced learners to underline unknown words whose meaning cannot be inferred from context and discuss with a partner which meanings are necessary for text comprehension. Guessing is a necessary strategy to compensate for gaps when reading an FL, but adequate use of a dictionary may be more efficient in many cases. Exercises on vocabulary are important, as vocabulary acquisition is such a vast field. Form-oriented tasks are one way of organizing vocabulary learning, another way is of course through tasks on semantic aspects of words, like looking for words belonging to the same semantic field. Form-oriented tasks include: looking for words with a certain stem or with certain affixes, recognizing parts of compound words. To improve automatic word recognition repeated processing in the same way, i.e. with similar tasks, is most efficient (Segalowitz Poulsen \& Komoda, 1991: 22).

Recognition exercises to relevant surface indicators (look for certain case endings, for plural forms, verb endings) and segmentation exercises (e.g., define and segment the noun phrases) will support perception and acquisition and so help prevent avoidance strategies. These exercises help structure linguistic form, which is important for retention. If the learners are familiar with the script such exercises are possible from a very early stage onwards in the acquisition process. In some cases, when surface 
indicators are irrelevant for comprehension, avoidance is of course a useful strategy. However, for productive skills even such indicators may have to be acquired.

To read the same text more than once is a good learning procedure for both poor and skilled readers, but improvement is important especially for poor readers (Levy 1993: 67f.; Levy, Barnes, Martin 1995, both for L1). "The message and its surface properties form a processing package that acts in a holistic fashion to mediate fluent reading" (Levy 1993: 64). In an FL, where the language is to a large extent new, more attention will have to be paid to word recognition and structure. Using the same text with different tasks is a way of facilitating the reading task.

\subsection{How to facilitate the work of the teacher}

Working with active and motivated learners is very rewarding. Preparing the many materials that are required to provide learners with a choice of texts and different kinds of tasks, to suit their interests can, however, be quite a burden. Considering the differences in learning style, a large number of different types of tasks and exercises has to be provided, all complying with, but also counteracting, aspects of learning styles. Questions on the contents and on some word meanings with feedback will have to be provided. This does not necessarily mean much work for the teacher; learners can create tasks for each other or even for themselves, with some control by the teacher. An easy exercise is making a gap filling exercise by leaving out whole words or case markers, verb endings etc. Another possibility is mixing up sentences and have the original order restored. Learners can also make content questions for each other, but this will mean some correction work for the teacher. Learners should be encouraged to make assignments for each other. To create a task can lead to more learning than to do the task. One problem is that learners often like to make very difficult exercises for each other. When learners make tasks for each other this can lead to discussions on learning activities or correct solutions and so, may lead to insight into their own learning process and to language awareness.

The kind of task included in Appendices I and II, which can be used with nearly any text, can be of great help to the teacher. Such lists, when used with the learners, should be shorter, and include only some of the tasks. In other words many different task lists can be made on the basis of those two lists and can be used with nearly any text. For learners such lists are useful, if they want to go on learning autonomously, especially if they know from school how to work with them.

Finding enough suitable (easy and interesting) texts appears to be easier for EFL than for German. The Belgian teachers, from Flemish Community schools of different types, VOLL and other, where German is an L4 for their classes, are setting up a scheme to exchange suitable materials.

\subsection{Conclusion}

The use of many types of exercises for one text is, especially for beginners, a useful way of keeping linguistic input limited and clear. As soon as basic competence has been acquired, independence, also from teacher-made tasks, should be encouraged in organizing the learning task and a very large and varied supply of texts should be aimed 
at. Reading for learning, however, implies at least some repeated confrontation with the input.

The teacher has to provide the framework for planning the learning process and (this will be necessary in most institutional contexts) impose a minimum number of objectives. It ought to be the learner's responsibility to plan and monitor the work and keep up with her/his own planning.

\section{BIBLIOGRAPHY}

Bernhardt, E. B. 1993. Reading Development in a Second Language: Theoretical, empirical and classroom perspectives. Norwood, NJ: Ablex.

Berry, D. C. \& Z. Dienes. 1993. Implicit Learning. Theoretical and Empirical Issues. Hillsdale, NJ: L. Erlbaum.

Borner, W. \& K. Vogel (eds.). 1994. Kognitive Linguistik und Fremdsprachenerwerb. Tubingen: G. Narr. Brown, G. 1990. “Text comprehension: Missing the cues”. Journal of Applied Linguistics 6, 37-47.

Carr, T. H. \& B.A. Levy (eds.). 1990. Reading Development. Component skills Approach. San Diego, CA: Academic Press.

Daneman, M. \& E. Reingold. 1995. "What eye fixations tell us about phonological recoding during reading”. In Henderson, J. M., M. Singer \& F. Ferreira (eds.), Reading and Language Processing. Mahwah, USA \& Hove, UK: L. Erlbaum, 25-50.

Ellis, R. 1990. Instructed Second Language Acquisition. Oxford: Basil Blackwell.

Gathercole, S. E. \& A.D. Baddeley. 1993. Working Memory and Language. Hove, UK \& Hillsdale, USA: L. Erlbaum.

Graf, P. \& M. E.J. Masson (eds.). 1993. Implicit memory. New Directions in Cognition, Development and Neuropsychology. Hillsdale, NJ: Erlbaum.

Henderson, J. M., M. Singer \& F. Ferreira (eds.). 1995. Reading and Language Processing, Mahwah, USA \& Hove, UK: L. Erlbaum.

Jonassen, D. H. \& B.L. Grabowski. 1993. Handbook of Individual Differences, Learning and Instruction. Hillsdale: L. Erlbaum.

Juel, C. 1995. "The messenger may be wrong, but the message may be right". Journal of Research in Reading 18, 146-153.

Kirsner, K., C. Speelman \& P. Schofield. 1993. "Implicit memory and skill acquisition: Is synthesis possible?”. Graf, P. \& M. E.J. Masson (eds.), Implicit memory. New Directions in Cognition, Development and Neuropsychology. Hillsdale, NJ: Erlbaum, 119-139.

Koda, K. 1993. "Transferred L1 strategies and L2 syntactic structure in L2 sentence comprehension ”. Modern Language Journal 77, 490-500.

Kolers, P. A. 1975. "Specificity of operations in sentence recognition”. Cognitive Psychology 7, 281-306. 
Lampola, R. (ed.). 1992. Report on Workshop 6A. Council of Europe, CC-LANG (92), Workshop 6A.

Lampola, R. (ed.). 1994. First progress report of the research and development programme of Workshop 6A. Council of Europe, CC-LANG (94) 7-1.

Levy, B. A. 1993. "Fluent rereading: an implicit indicator of reading skill development". In Graf, P. \& M. E.J. Masson (eds.), Implicit memory. New Directions in Cognition, Development and Neuropsychology. Hillsdale, NJ: Erlbaum, 49-73.

Levy, B. A., L. Barnes \& L. Martin. 1995. “Transfer of fluency across repetitions and across texts". In Henderson, Singer \& Ferreira, 273-299.

Levy, B. A. \& J. Hinchley. 1990. "Individual and developmental differences in the acquisition of reading skills”. In Carr \& Levy, 81-128.

Lutjeharms, M. 1988. "Lesen in der Fremdsprache. Versuch einer psycholinguistischen Deutung am Beispiel". Deutsch als Fremdsprache. Bochum: AKS-Verlag.

Lutjeharms, M. 1991. “Lexical access and foreign language acquisition”. Interface 5, 73-81.

Lutjeharms, M. 1992. “Report on the working group on strategies". In Lampola, 34-42.

Lutjeharms, M. 1994a. "Developing autonomous learning for weak learners focusing on comprehension strategies (working group on strategies)". In Lampola 1994, 16-32.

Lutjeharms, M. 1994b. “Worterkennen beim Lesen einer Fremdsprache”. In Borner \& Vogel,149-167.

Lutjeharms, M. 1994c. "Lesen in der Fremdsprache: Zum Leseprozess und zum Einsatz der Lesefertigkeit im Fremdsprachenunterricht”. Zeitschrift für Fremdsprachenforschung 5, 36-77.

McDonald, J. L. \& L.K. Heilenrnan. 1991. "Determinants of cue strength in adult first and second language speakers of French". Applied Linguistics 12, 313-348.

Niemela, A.-M. 1995. "A report of the experiment of autonomous learning at Kapyla Vocational Institute, Helsinki, Finland 1992-1993. In Stenberg, K. (ed.), Report on Workshop 6B. “"Learning fo learn' language in vocationally oriented education” Uppsala, Sweden, 11-17 December 1994, Council of Europe, CC-Lang, 75-78.

Ohman, L. 1995. “A classroom example of learner autonomy and strategies”. In Stenberg, K. (ed.), Report on Workshop 6B. "'Learning fo learn' language in vocationally oriented education" Uppsala, Sweden, 11-17 December 1994, Council of Europe, CC-Lang(95), 237-238.

Papagno, C., T. Valentine \& A. Baddeley. 1991. "Phonological short-term memory and foreign-language vocabulary learning”. Journal of Memory and Language 30, 331-347.

Perfetti, C. A. 1995. Cognitive research can inform reading education". Journal of Research in Reading 18, 106-115.

Sahu, S. \& Kar, A. 1994. "Reading comprehension and information processing strategies". Journal of Research in Reading 17, 3-18.

Sasaki, M. 1993. "Relationships among second language proficiency, foreign language aptitude, and intelligence: A protocol analysis". Language Learning 43, 469-505.

Segalowitz, N. 1986. "Skilled reading in the second language ». In Vaid, J. (ed.), Language Processing in Bilinguals: Psycholinguistic and neuropsychological perspectives. Hillsdale, NJ: Erlbaum, 3-19.

Segalowitz, N. \& M. Hébert. 1990. "Phonological recording in the first and second language reading of skilled bilinguals”. Language Learning 40, 503-538. 
Segalowitz, N., C. Poulsen \& M. Komoda. 1991. "Lower level components of reading skill in higher level bilinguals: Implications for reading instruction”. AILA Review 8, 15-30.

Stanovich, K. E. \& P.J. Stanovich. 1995. "How research might inform the debate about early reading acquisition". Journal of Research in Reading 18, 87-105.

Stenberg, K. (ed.). 1995. Report on Workshop 6B. “'Learning fo learn' language in vocationally oriented education” Uppsala, Sweden, 11-17 December 1994, Council of Europe, CC-Lang.

Vaid, J. (ed.). 1986. Language Processing in Bilinguals: Psycholinguistic and neuropsychological perspectives. Hillsdale, NJ: Erlbaum.

Wong, M. Y. \& G. Underwood. 1996. "Do bilingual children read words better in lists or in contexts?". Journal of Research in Reading 19, 61-76.

My thanks to Michael Whitburn for reading through the text.

\section{APPENDIXES}

Examples of tasks that also facilitate the work of the teacher (worksheets)

Appendix 1 Vocabulary tasks (working with texts)

\section{1) Unknown words}

- Do you need this word in order to understand the text?

- If so, can you find the meaning without a dictionary? Is it a noun, verb...? Does context help? Do you recognize parts of the word?

If you can't guess or don't feel completely sure, use a dictionary to check your guess.

\section{2) Learning words}

- You have to learn $\mathrm{x}$ words from this text:

Which words did you choose?

Why those? frequent, important (for), I like the sound

- How are you going to learn them?

repeat (oral, written) the word in a/part of a/ sentence

repeat the word only with the help of another word (that looks similar, has a common syllable or?)

with a situation (what kind of relation to the word?)

I single out the word in the text and read it or the paragraph it is in several times over...

\section{3) Design an exercise for your friends}

- Choose 5 (or more) words from the text that belong together

they are about the same kind of subject (such as: music, sports, food...)

they provide the same kind of indication (such as: numbers, places, time, negatives...)

they are the same kind of words (such as : nouns, verbs, adjectives, prepositions...).

- Add 1 word that does not belong to this group and write all the words down (in any order).

- Ask your friends to find the word that does not belong to the group.

\section{4) Can you think of any other exercises?}




\section{Appendix 2 Working with texts}

- Why did you choose this text?

- If it is because of the subject: How did you gain some insight into the content? Title?

Pictures? A quick glance at the text? What else?

- Read the text as fast as you can to check whether your idea about the content was correct.

- Are you still interested in the text? If so, complete (some of) the following tasks. If not, choose another text.

- Read the text more thoroughly. Underline the words you do not understand.

- Are there any parts of the text you find easy? What are they about?

- Are there any parts of the text you find particularly difficult? Why? e.g., many difficult words, long sentences, I don't know enough about the subject...

What kind of help would be most effective? A dictionary? Help from a friend or from the teacher? For what problem and why?

If you could look up only half the words you don't understand (or... words), which would you decide to look up?

Why not the others?

e.g. - Can you guess their meaning from the context?

Do you think they are not that important?

Are you not interested in that part of the text?

There are so many unknown words, so I simply chose at random...

Why those?

e.g. - The word seems important (Why?).

I cannot understand the sentence/passage without it.

It occurs frequently (in the text).

I cannot guess it.

To check whether my guess was correct.

This part of the text seems interesting.

Curiosity (e.g. the word looks funny, it looks like a word I know)...

Then look up the words, if you are sure you need or want the information. Before doing so, try to decide, whether the word is a noun, verb, adjective, etc.

- Read the text again. Are there any other words you would like to look up? Which ones?

- Which new words from the text are you going to learn? See vocabulary tasks $2+3$.

- Single out words in the text that are related to... (aspect of content).

- Single out words in the text with... (certain parts of words such as affixes, stem, inflectional indicators).

- Underline the most important words in the text (adopt a new way of underlining or marking, or use a new copy). 
- Make a summary of the text by underlining the main ideas (the most important words probably belong to them).

- Rearrange those main ideas at random and write them down in the rearranged order. Ask a friend to find the original order using a new copy of the text. Correct her/his work, if necessary.

- Write questions on text content for somebody who has worked with the same text. Ask her/him to do the same for you.

- Cover the new words you looked up/learned (with whitener or black them out) and number the gaps. Complete the exercise giving the right word for each gap number later on (e.g., during the next lesson or as homework).

- Ask a friend to produce a gap-filling test for you on the text. You can suggest s/he cover either whole words or word endings.

- Can you think of any other exercises on the text?

- Think about everything you have learned with the help of this text. Check your knowledge at some later time by re-reading the text or completing one of the exercises. Don't forget you learn a lot, when you reread the text several times over, paying attention to what you are doing, and when you complete exercises that involve re-reading.

\section{ABSTRACTS}

Vocationally-oriented language learners (VOLL) have varied foreign language (FL) needs. It is useful to prepare learners for the later autonomous acquisition of other language skills and different vocabulary that they may encounter in their careers. Learning how to work with FL texts can achieve this goal, even for weak learners. We look at the problems facing weak learners when reading their own language, which can be related to memory and information processing. We then show how important reading a foreign language is for improving linguistic skills and how learners need to be motivated in class.

Les besoins en langues étrangères des étudiants en formation professionnelle sont très variés. Il est important de préparer les apprenants à acquérir en autonomie d'autres compétences linguistiques et des vocabulaires différents pour qu'ils puissent les utiliser plus tard au cours de leur carrière. Apprendre à travailler à partir de textes en langue étrangère leur permettra d'atteindre cet objectif, même s'il s'agit d'apprenants de faible niveau. Nous étudions les problèmes auxquels sont confrontés en lecture dans leur langue maternelle les apprenants de faible niveau, problèmes qui peuvent être liés à la mémoire et au traitement des informations. Nous montrons ensuite l'importance de la lecture d'une langue étrangère dans l'amélioration des compétences linguistiques et l'importance de la motivation des apprenants en classe.

\section{INDEX}

Mots-clés: apprenant d'un faible niveau, compréhension écrite, formation professionnelle Keywords: reading comprehension, vocationally-oriented language learning, weak learner 


\section{AUTHOR}

\section{MADELINE LUTJEHARMS}

Madeline Lutjeharms enseigne à l'Université libre, Vrije Universiteit, de Bruxelles.

Madeline.Lutjeharms@vub.ac.be 